\title{
Differences in Functional Expression of Connexin43 and Nav1.5 by Pan- and Class-Selective Histone Deacetylase Inhibition in Heart
}

\author{
Xian Zhang ${ }^{1}\left(\mathbb{D}\right.$, Dakshesh Patel ${ }^{1}$ (D), Qin $\mathrm{Xu}^{1,+}$ and Richard Veenstra ${ }^{1,2, *}$ \\ 1 Department of Pharmacology, State University of New York (SUNY) Upstate Medical University, \\ Syracuse, NY 13210, USA; ZhangXi@upstate.edu (X.Z.); daksheshpatel10@gmail.com (D.P.); \\ xuqinblue@gmail.com (Q.X.) \\ 2 Department of Cell and Molecular Biology, SUNY Upstate Medical University, Syracuse, NY 13210, USA \\ * Correspondence: veenstrr@upstate.edu; Tel.: +315-464-5145 \\ + Current Address: Department of Psychiatry, Brain Research Center, The University of British Columbia, \\ 2255 Wesbrook Mall, Vancouver, BC V6T 1Z3, Canada.
}

Received: 15 July 2018; Accepted: 2 August 2018; Published: 4 August 2018

\begin{abstract}
Class-selective histone deacetylase (HDAC) inhibitors were designed to improve safety profiles and therapeutic effectiveness in the treatment of multiple cancers relative to pan-HDAC inhibitors. However, the underlying mechanisms for their therapeutic and cardiotoxic potentials remain poorly understood. Cardiac sodium currents $\left(\mathrm{I}_{\mathrm{Na}}\right)$ and gap junction conductance $\left(\mathrm{g}_{\mathrm{j}}\right)$ were measured by whole cell patch clamp techniques on primary cultures of neonatal cardiomyocytes. Cardiac Nav1.5 sodium channel and connexin43 (Cx43) gap junction protein levels were assessed by Western blot analyses. Panobinostat produced concentration-dependent reductions in ventricular $\mathrm{g}_{\mathrm{j}}$, peak $\mathrm{I}_{\mathrm{Na}}$ density, and $\mathrm{Na}_{\mathrm{V}} 1.5$ protein expression levels. Membrane voltage $\left(\mathrm{V}_{\mathrm{m}}\right)$-dependent activation of $\mathrm{I}_{\mathrm{Na}}$ was shifted by +3 to $6 \mathrm{mV}$ with no effect on inactivation. Entinostat $(1 \mu \mathrm{M})$ did not affect ventricular $\mathrm{g}_{\mathrm{j}}$, peak $\mathrm{I}_{\mathrm{Na}}$ density, or $\mathrm{I}_{\mathrm{Na}}$ activation. However, the $\mathrm{I}_{\mathrm{Na}}$ half-inactivation voltage $\left(\mathrm{V}_{1 / 2}\right)$ was shifted by $-3.5 \mathrm{mV}$. Ricolinostat had only minor effects on ventricular $\mathrm{g}_{\mathrm{j}}$ and $\mathrm{I}_{\mathrm{Na}}$ properties, though $\mathrm{I}_{\mathrm{Na}}$ activation was shifted by $-4 \mathrm{mV}$. Cx43 and $\mathrm{Na}_{\mathrm{V}} 1.5$ protein expression levels were not altered by class-selective HDAC inhibitors. The lack of effects of class-selective HDAC inhibitors on ventricular $\mathrm{g}_{\mathrm{j}}$ and $\mathrm{I}_{\mathrm{Na}}$ may help explain the improved cardiac safety profile of entinostat and ricolinostat.
\end{abstract}

Keywords: histone deacetylase inhibitors; class-selective; gap junction; cardiac sodium channel; connexin $43 ; \mathrm{Na}_{\mathrm{V}} 1.5$; cardiotoxicity

\section{Introduction}

Histone acetyltransferases (HATs) and histone deacetylases (HDACs) regulate the dynamic balance between acetylation and deacetylation of lysine residues of both histone and non-histone proteins. Non-histone proteins are involved in numerous critical cellular physiological functions, including apoptosis, autophagy and DNA damage repair [1]. HDACs have been suggested to be overexpressed in tumor cells and alter the expression and function of many tumor suppressor genes like p53 [2,3]. However, the four U. S. Food and Drug Administration (FDA) approved pan-HDAC inhibitors are limited to non-solid tumors and have been reported to cause serious cardiotoxicities such as QT interval prolongation, ventricular arrhythmia and unexpected sudden cardiac death [4-7]. In order to improve their effectiveness on solid tumors as well as to minimize their cardiac side effects, a new generation of HDAC inhibitors, class-selective HDAC inhibitors were designed and developed [8]. Significantly, some of them have shown promising therapeutic effects against leukemias 
as well as breast and lung cancers with less cardiotoxicities [9-12]. However, the mechanisms behind their therapeutic and lack of cardiotoxic potentials is still unclear.

Our previous studies have suggested the involvement of the inward depolarizing cardiac sodium current $\left(\mathrm{I}_{\mathrm{Na}}\right)$ and connexin43 (Cx43) on pan-HDAC inhibitor induced cardiac side effects $[13,14]$. Physiologically, Cx43, the predominant gap junction protein in the ventricles, is required for synchronous longitudinal and transverse conduction of cardiac action potentials throughout the heart [15]. Furthermore, cardiac $\mathrm{I}_{\mathrm{Na}}$ through the voltage-gated cardiac sodium channel $\left(\mathrm{Na}_{\mathrm{v}} 1.5\right)$ is vital for normal cardiac electrical activity [16]. Gain or loss of function of this protein is related to long QT syndrome or Brugada syndrome [17]. Previous research in our laboratory has indicated that both the protein expression of $\mathrm{C} \times 43$ and $\mathrm{Na}_{\mathrm{v}} 1.5$ and their resultant electrophysiological currents were reduced by pan-HDAC inhibition $[13,14]$. These functional reductions in rapid depolarization and electrical coupling likely contribute to decreased excitability and slowed conduction, thereby increasing the vulnerability to reentrant arrhythmias. Since entinostat (MS-275), a class I selective HDAC inhibitor, apparently causes minimal cardiotoxic effects $[7,8,18]$, we hypothesize that class-selective HDAC inhibition does not cause the functional downregulation of the cardiac $\mathrm{I}_{\mathrm{Na}}$ or gap junction conductance $\left(g_{j}\right)$ observed with the first two FDA-approved pan-HDAC inhibitors, vorinostat (VOR, Zolinza $\left.{ }^{\circledR}\right)$ and romidepsin $\left(F K 228\right.$, Istodax $\left.{ }^{\circledR}\right)[13,14]$. In this study, we examine the effects of another FDA-approved HDAC inhibitor, panobinostat (LBH589, Farydak ${ }^{\circledR}$ ), and two clinical trial class-selective HDAC inhibitors, entinostat (MS-275, HDAC class I selective), and ricolinostat (ACY-1215, HDAC class IIb selective), on Cx43-mediated cardiac gap junction coupling and excitatory cardiac sodium current density mediated primarily by $\mathrm{Na}_{\mathrm{V}} 1.5$.

\section{Results}

\subsection{Inhibition of Cardiac HDAC Activity by Pan- and Class-Selective HDAC Inhibitors}

The inhibitory action of panobinostat, entinostat, and ricolinostat on total HDAC activity in cultured ventricular cardiomyocytes was assessed using the fluorometric Fluor de Lys assay as performed in our previous studies $[13,14]$. As with Trichostatin A (TSA), vorinostat (VOR), and romidepsin (FK228), the inhibitory dose-response curves for the three HDAC inhibitors used in this study were best described by a double exponential decay curve, indicative of two inhibitory sites with a $>10$-fold difference in the apparent $\mathrm{IC}_{50}$ s between the high and low affinity HDAC inhibitory sites (Figure 1). The fluorometric data was fitted with the equation RFU $=A_{1} \cdot \exp \left(-[\mathrm{HDACI}] / \mathrm{C}_{1}\right)$ $+\mathrm{A}_{2} \cdot \exp \left(-[\mathrm{HDACI}] / \mathrm{C}_{2}\right)+\mathrm{B}$ where $\mathrm{Ax}_{\mathrm{X}}=$ the amplitude of each exponential component, [HDACI] $=$ HDAC inhibitor concentration, $\mathrm{C}_{\mathrm{X}}=$ the decay constant for each exponential component, $\mathrm{B}=$ the background fluorescence count constant, $\mathrm{RFU}=$ relative fluorescence units = total counts for each sample, and the $\mathrm{IC}_{50}=0.693 \cdot \mathrm{C}_{X}$ for each apparent inhibitory site. The fit parameters for all HDACIs examined thus far are listed in Table 1.

Thus far, all HDAC inhibitors tested on cultured neonatal mouse ventricular cardiomyocytes (NMVMs) exhibit two apparent $\mathrm{IC}_{50}$ s for total HDAC activity, which we hypothesize corresponds to the different classes (I, II, IV) and subclasses (IIa/b) of zinc-dependent HDACs. Entinostat is reported to inhibit HDACs 1 and 3 with an $\mathrm{IC}_{50}<1 \mu \mathrm{M}$ and exhibits incomplete inhibition of HeLa nuclear extract HDAC activity with an $\mathrm{IC}_{50}$ of $11 \mu \mathrm{M}$ [19]. Our apparent high and low affinity $\mathrm{IC}_{50}$ s for total cardiac HDAC activity of 0.43 and $12.9 \mathrm{nM}$ are in close agreement with these $\mathrm{IC}_{50}$ values. Ricolinostat possesses $>10$-fold selectivity for HDAC 6 over HDACs 1 , 2, and 3 with $\mathrm{IC}_{50}$ s of approximately 5 and $50 \mathrm{nM}$, respectively [20]. Our observed $\mathrm{IC}_{50} \mathrm{~s}$ of 12 and $140 \mathrm{nM}$ are approximately 2 times higher than those reported $\mathrm{IC}_{50}$ s, but are otherwise consistent with HDAC6 and HDAC1-3 inhibition. 

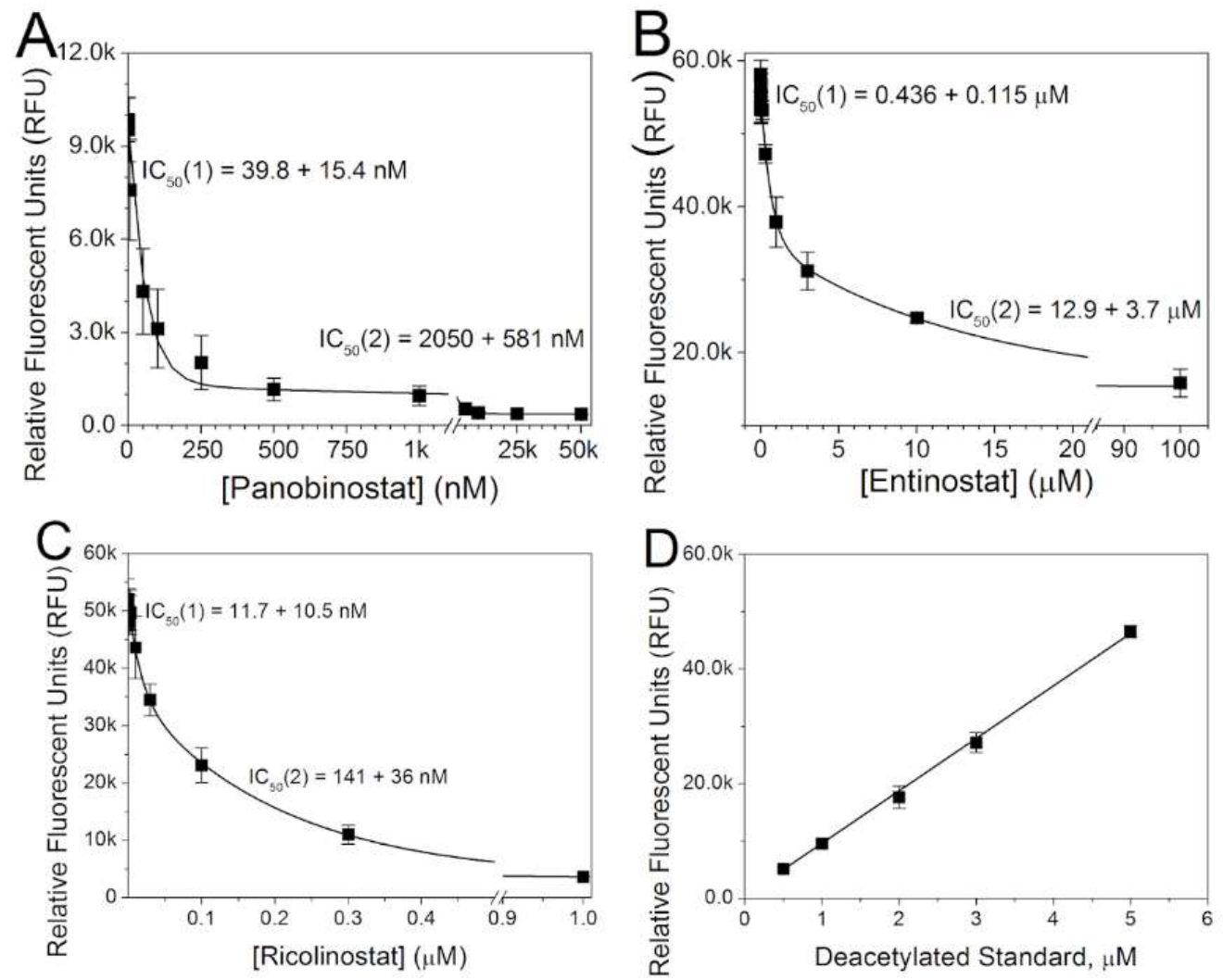

Figure 1. Histone deacetylase (HDAC) activity assays for pan- and class-selective HDAC inhibitors. (A) The total HDAC inhibition curve for neonatal mouse ventricular cardiomyocytes treated for 18-24 $\mathrm{h}$ with increasing concentrations of panobinostat. Two $\mathrm{IC}_{50} \mathrm{~s}$ of approximately 40 and $2000 \mathrm{nM}$ are apparent. (B) The cardiomyocyte HDAC inhibition curve for the class I HDAC selective inhibitor entinostat. Again, the HDAC activity curve was best fit with a double exponential function. (C) The ventricular cardiomyocyte HDAC inhibition curve for the HDAC6 class IIb HDAC inhibitor ricolinostat exhibits two distinct $\mathrm{IC}_{50} \mathrm{~s}$ for total HDAC activity. (D) The standard curve for the deacetylated fluorescent Fluor-de-Lys product showing a linear response. All Fluor-de-Lys HDAC activity assays were performed in triplicate and the average \pm SEM values are shown. The parameters for the double exponential fits of the dose-response curves are listed in Table 1.

Table 1. HDAC inhibitor Activity Assays.

\begin{tabular}{|c|c|c|c|c|c|c|c|c|}
\hline HDACI & $\mathbf{A}_{1}$ & $\mathrm{C}_{1}(\mathrm{nM})$ & $\mathrm{IC}_{50}(1)(\mathrm{nM})$ & $\mathbf{A}_{2}$ & $C_{2}(n M)$ & $\mathrm{IC}_{50}(2)(\mathrm{nM})$ & B & $\mathbf{R}^{2}$ \\
\hline TSA * (RFU) & $2829 \pm 219$ & $10.6 \pm 1.3$ & $7.3 \pm 0.9$ & $298 \pm 71$ & $258 \pm 76$ & $179 \pm 53$ & $84 \pm 7$ & 0.98 \\
\hline VOR * (\% RFU) & $48.8 \pm 7.7$ & $140 \pm 30$ & $97 \pm 21$ & $44.1 \pm 7.1$ & $1086 \pm 312$ & $753 \pm 216$ & $6.1 \pm 2.4$ & 0.99 \\
\hline $\mathrm{FK} 228^{+}(\%$ RFU $)$ & $63.5 \pm 5.3$ & $7.9 \pm 0.9$ & $5.5 \pm 0.6$ & $27.7 \pm 2.8$ & $2524 \pm 678$ & $1749 \pm 470$ & $8.8 \pm 1.4$ & 0.99 \\
\hline LBH589 (RFU) & $8322 \pm 711$ & $57.4 \pm 22.2$ & $39.8 \pm 15.4$ & $927 \pm 357$ & $2959 \pm 838$ & $2050 \pm 581$ & $374 \pm 3$ & 0.96 \\
\hline MS-275 (RFU) & $20,111 \pm 3080$ & $629 \pm 166$ & $436 \pm 115$ & $20,106 \pm 2150$ & $12,926 \pm 3655$ & $8958 \pm 2533$ & $15,408 \pm 1138$ & 0.97 \\
\hline ACY-1215 (RFU) & $14,914 \pm 6840$ & $16.9 \pm 15.1$ & $11.7 \pm 10.5$ & $32,744 \pm 6835$ & $204 \pm 52$ & $141 \pm 36$ & $3369 \pm 263$ & 0.99 \\
\hline
\end{tabular}

\subsection{Effects of Class-Selective HDAC Inhibitors on Gap Junction Coupling}

Previous results with three pan-HDACIs consistently showed a dose-dependent decrease in cardiac ventricular gap junction conductance $\left(g_{j}\right)$ [14]. To assess whether this observation holds true for panobinostat and if class I and IIb HDAC inhibition has similar effects, $g_{j}$ was measured in NMVM cell pairs after 18-24 h treatment with varying concentrations of panobinostat, entinostat, and ricolinostat. Consistent with previous findings, pan-HDAC inhibition by panobinostat produced a significant dose-dependent decrease in ventricular $g_{j}$ (Figure 2A). The concentration-dependent decline in $g_{j}$ 
by panobinostat was best fit by an exponentially decaying function with an amplitude of 48.5 and exponential decay constant of $320 \mathrm{nM}$ (gray points and curve). By contrast, class I HDAC-selective inhibition by 1 or $2.5 \mu \mathrm{M}$ entinostat did not reduce $g_{j}$, though a significant reduction in $g_{j}$ was obtained with $5 \mu \mathrm{M}$ entinostat, 10 -fold higher than the observed high affinity $\mathrm{IC}_{50}$ that likely corresponds to the class I-selective HDAC inhibition (Figure 2B). Linear regression fits correlated poorly with the $g_{j}$ - [entinostat] relationship (gray points and dashed gray line). Class IIb HDAC inhibition with 10 or $25 \mathrm{nM}$ ricolinostat produced modest but non-significant increases and decreases in $\mathrm{g}_{\mathrm{j}}$, respectively (Figure 2C). Linear regression analysis of this data produced a straight line with a slope of only $-0.2 \mathrm{~ns} / \mathrm{nM}$ ricolinostat (gray points and line). These results suggest that class-selective HDAC inhibition does not affect ventricular $g_{j}$ as dramatically as pan-HDAC inhibition, and even then only produces downregulatory effects only when HDACI concentrations were high enough to begin to exceed the HDAC class-selective properties of entinostat and ricolinostat.
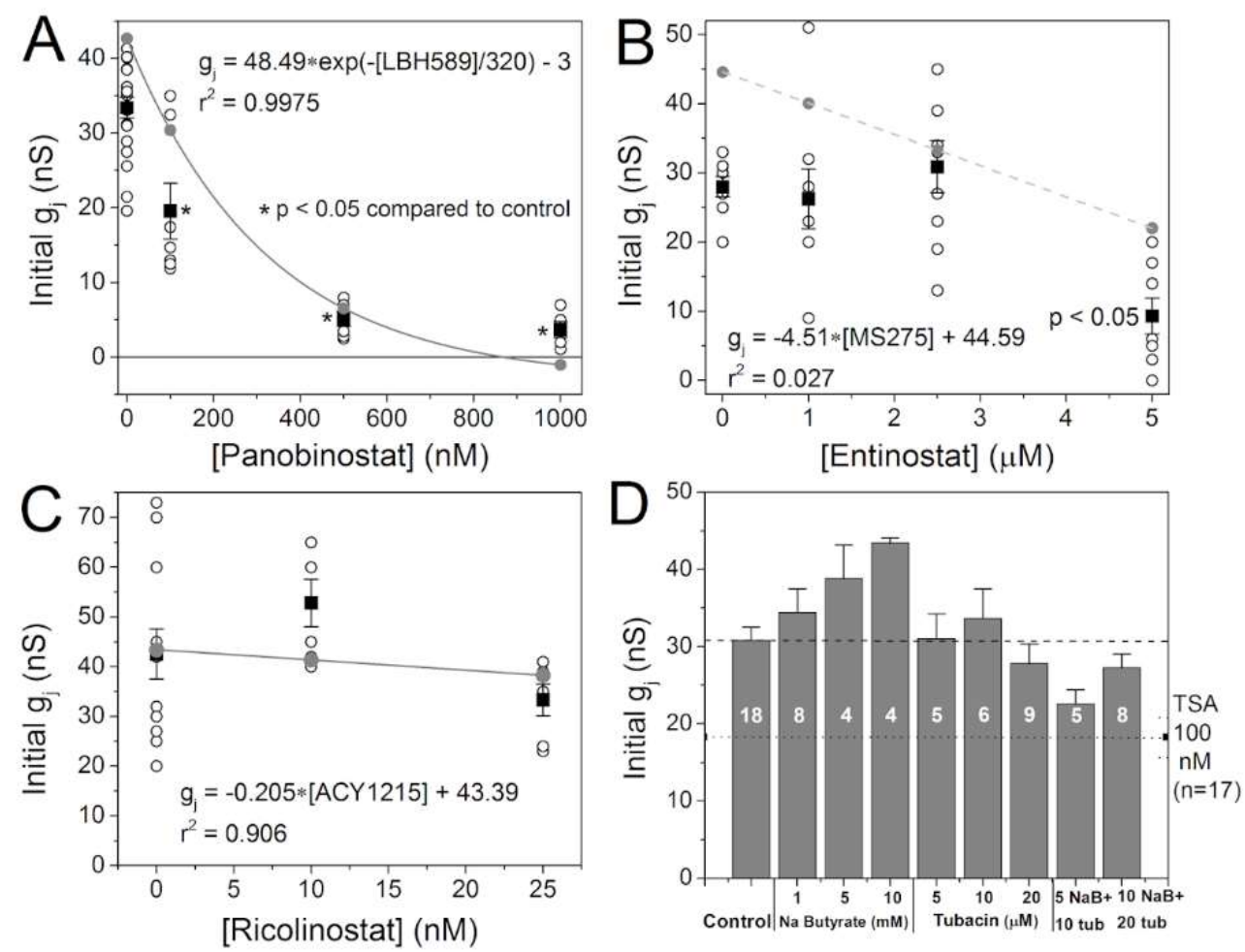

Figure 2. Effects of pan- and class-selective HDAC inhibition on gap junction coupling. (A) The gap junction conductance $\left(\mathrm{g}_{\mathrm{j}}\right)$ was measured between neonatal mouse ventricular cardiomyocytes (NMVMs) treated with 0, 100, 500, or $1000 \mathrm{nM}$ panobinostat for 18-24 h in culture. Pan-HDAC inhibition reduced $g_{j}$ in a concentration-dependent manner. (B) Class I HDAC selective inhibition with entinostat had no effect on ventricular $\mathrm{g}_{\mathrm{j}}$ except at the highest, and least selective, concentration tested. (C) Ricolinostat, a class IIb HDAC6-selective inhibitor produced a slight, but non-significant, increase and then decrease in ventricular $g_{j}$ as the concentration was increased from 10 to $25 \mathrm{nM}$. (D) The effect of a weak HDAC class I/Ilb inhibitor, sodium butyrate (NaB), and the prototype HDAC6 inhibitor, tubacin, on $g_{j}$ were tested independently and in combination [21-23]. NaB non-significantly increased $g_{j}$ in a concentration-dependent manner while tubacin (tub) produced a non-significant increase and then decrease in $\mathrm{g}_{\mathrm{j}}$ with increasing concentration. When concentrations of $\mathrm{NaB}$ and tubacin that increased $g_{j}$ by $26 \%$ and $9 \%$ respectively were applied in combination, $g_{j}$ decreased by $26 \%$, indicating an opposite and negative response when class I and IIb HDAC inhibition is combined. 
Prior to the development of entinostat and ricolinostat, we explored the combinatorial effect of class I and IIb HDAC inhibition using sodium butyrate and the prototypical HDAC6 inhibitor, tubacin [21]. Sodium butyrate $(\mathrm{NaB})$ is a short chain fatty acid non-specific HDAC inhibitor with $\mathrm{mM}$ affinities for the class II HDACs, even weaker and incomplete inhibitory activity of class IIa HDAC isoforms, and no activity against the class IIb HDAC6 [22,23]. 4-phenylbutyrate (4-PB) belongs to this group of HDAC inhibitors and is known to upregulate $\mathrm{Cx} 43$ expression in human glioblastoma and embryonic kidney cells $[24,25]$. The HDAC inhibitory profiles of the HDAC inhibitors used in this study are listed in Table 2. The HDAC inhibition assays from the cited studies were performed using different reagents, but the highlighted columns indicate HDAC activities measured using the Fluor-De-Lys ${ }^{\circledR}$ substrate on recombinant human HDACs [23]. Sodium butyrate increased ventricular $\mathrm{g}_{\mathrm{j}}$ in a dose-dependent manner while tubacin exhibited a biphasic response, causing a slight increase in $\mathrm{g}_{\mathrm{j}}$ or no effect at low doses, followed by a slight decrease at the highest tested dose of $20 \mu \mathrm{M}$ (Figure 2D). However, when we combined $5 \mathrm{mM} \mathrm{NaB}$ with $10 \mu \mathrm{M}$ tubacin, concentrations of these two HDAC inhibitors that increased $\mathrm{g}_{\mathrm{j}}$ slightly when applied individually, the opposite effect occurred. The reduction in $\mathrm{g}_{\mathrm{j}}$ when combining $5 \mathrm{mM} \mathrm{NaB}$ and $10 \mu \mathrm{M}$ tubacin was $25 \%$ relative to control $\mathrm{g}_{\mathrm{j}}$ values and $40 \%$ relative to $5 \mathrm{mM} \mathrm{NaB}$, suggesting that combinatorial class I and Ilb HDAC inhibition negatively affects ventricular gap junction coupling while inhibition of either of these two classes of HDACs alone has negligible effects.

Table 2. Inhibitory constants for HDAC inhibitors used in this study.

\begin{tabular}{|c|c|c|c|c|c|c|c|c|}
\hline \multirow{2}{*}{ HDACI } & LBH589 & LBH589 & MS-275 & MS-275 & MS-275 & ACY-1215 & Tubacin & VPA \\
\hline & $(\mathrm{nM})[23]$ & $(\mathrm{nM})[26]$ & (nM) [19] & $(\mathrm{nM})[23]$ & $(\mathrm{nM})[26]$ & $(n M)[20]$ & $(\mathrm{nM})[26]$ & $(\mathrm{nM})[23]$ \\
\hline HDAC & $\mathrm{IC}_{50}$ & $\mathbf{K}_{\mathrm{I}}$ & $\mathrm{IC}_{50}$ & $\mathrm{IC}_{50}$ & $\mathrm{~K}_{\mathrm{I}}$ & $\mathrm{IC}_{50}$ & $\mathrm{~K}_{\mathrm{I}}$ & $\mathrm{IC}_{50}$ \\
\hline HDAC1 & $3 \pm 0$ & $1.00 \pm 0.1$ & $180 \pm 70$ & $181 \pm 62$ & $22 \pm 2$ & 58 & $28 \pm 4$ & $1.584 \times 10^{+6} \pm 0.3$ \\
\hline HDAC2 & $3 \pm 0$ & $0.65 \pm 0.1$ & --- & $1155 \pm 134$ & $65 \pm 5$ & 48 & $42 \pm 3.5$ & $3.07 \times 10^{+6} \pm 0$ \\
\hline HDAC3 & $4 \pm 1$ & $1.1 \pm 0.15$ & $740 \pm 250$ & $2311 \pm 803$ & $360 \pm 15$ & 51 & $275 \pm 320$ & $3.07 \times 10^{+6} \pm 0$ \\
\hline HDAC8 & $248 \pm 11$ & $105 \pm 20$ & $44,900 \pm 18,100$ & $>100,000$ & --- & 100 & $170 \pm 10$ & $7.442 \times 10^{+6} \pm 2.74$ \\
\hline HDAC6 & $61 \pm 1$ & $1.50 \pm 0.5$ & $>100,000$ & $>100,000$ & --- & 4.7 & $16 \pm 2$ & $>100,000$ \\
\hline HDAC4 & $12 \pm 5$ & $550 \pm 50$ & --- & $>100,000$ & --- & 7000 & $17,000 \pm 2500$ & -- \\
\hline HDAC5 & -- & $80 \pm 10$ & --- & -- & --- & 5000 & $1500 \pm 250$ & --- \\
\hline HDAC7 & $14 \pm 7$ & $4550 \pm 315$ & --- & $>100,000$ & --- & 1400 & $8500 \pm 1500$ & $>100,000$ \\
\hline HDAC9 & $3 \pm 2$ & $3200 \pm 200$ & --- & $505 \pm 37$ & --- & $>10,000$ & --- & $>100,000$ \\
\hline
\end{tabular}

$>100,000=$ incomplete inhibition at $100 \mu \mathrm{M}$ [HDACI] [23]; VPA = valproic acid, another short chain fatty acid low-affinity HDAC inhibitor.

\subsection{Effects of Class-Selective HDAC Inhibitors on Peak Cardiac $\mathrm{Na}^{+}$Current Density}

As with gap junction coupling, previous results with pan-HDAC inhibitors have revealed a significant reduction in sodium current density [13]. Thus, we examined the effect of panobinostat on the cardiac $\mathrm{Na}^{+}$current density in NMVMs. True to form, panobinostat decreased the cardiac sodium current density in a dose-dependent manner (Figure 3A,B). Contrary to pan-HDAC inhibition, class I HDAC inhibition with $1 \mu \mathrm{M}$ entinostat had no significant effect on the peak $\mathrm{Na}^{+}$current density (Figure 3C). Surprisingly, the opposite effect was seen with HDAC6 inhibition by $25 \mathrm{nM}$ ricolinostat (Figure 3D,E). Despite the apparent $93 \%$ increase in peak $\mathrm{I}_{\mathrm{Na}}$ with $25 \mathrm{nM}$ ricolinostat, the mean values did not achieve statistical significance ( $p=0.054$, one-way ANOVA). 


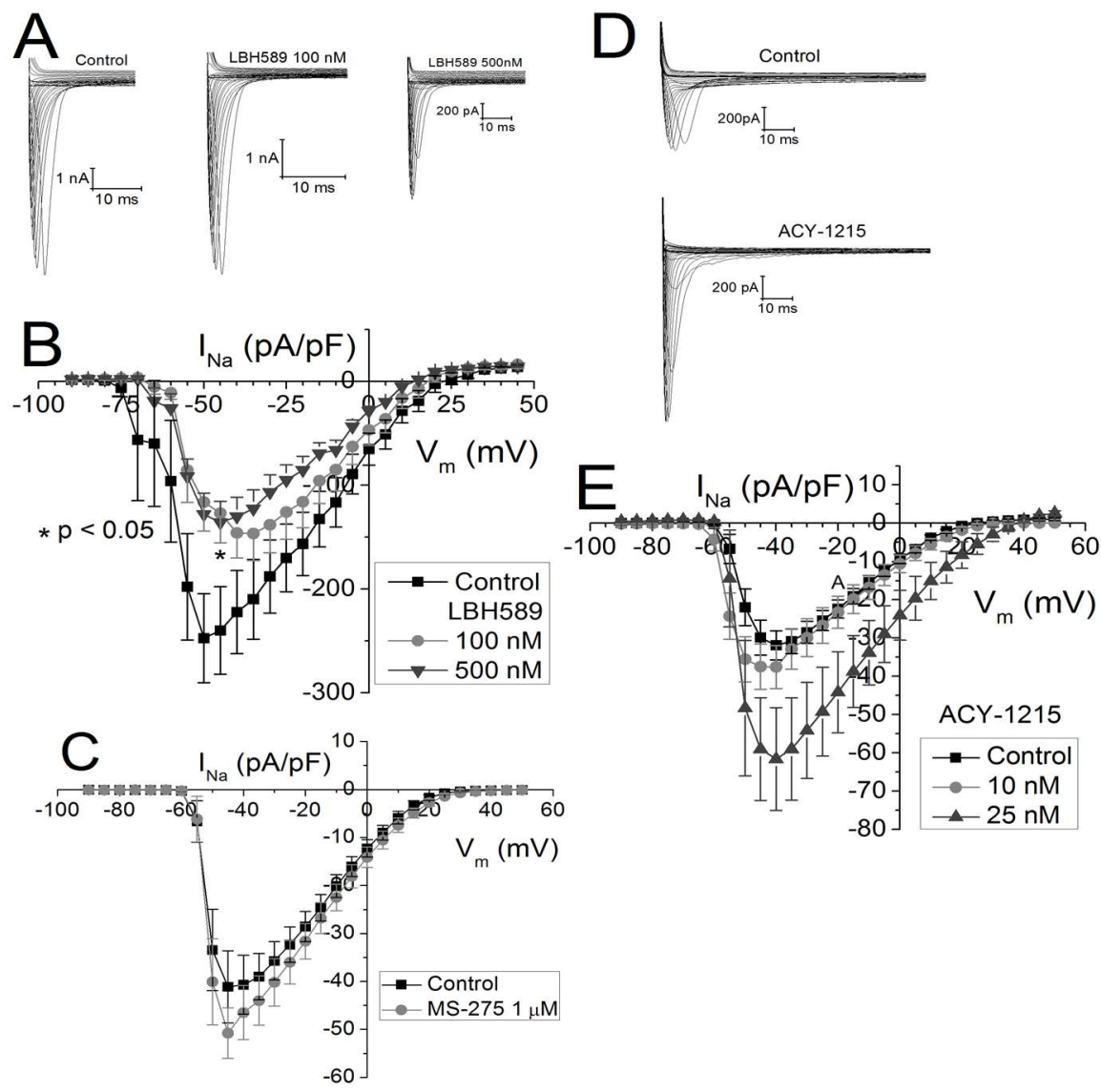

Figure 3. Peak cardiac $\mathrm{I}_{\mathrm{Na}}$ effects of pan- and class-selective HDAC inhibition. (A) Families of ventricular cardiomyocyte $\mathrm{I}_{\mathrm{Na}}$ current traces produced in response to depolarizing voltage clamp steps from a holding potential of $-120 \mathrm{mV}$ before and after treatment with 100 or $500 \mathrm{nM}$ panobinostat (LBH589). (B) Average $\mathrm{I}_{\mathrm{Na}}$ current-voltage (I-V) relationships from control $(n=8)$ and LBH589 treated cells $(n=8,10)$ illustrating a concentration-dependent decrease in peak $\mathrm{I}_{\mathrm{Na}}$ density $(\mathrm{pA} / \mathrm{pF})$ with pan-HDAC inhibition. (C) Average $\mathrm{I}_{\mathrm{Na}}-\mathrm{V}_{\mathrm{m}}$ relationships for control $(n=9)$ and $1 \mu \mathrm{M}$ entinostat (MS-275, $n=8$ ) treated NMVMs indicates that class I HDAC inhibition does not affect the cardiac $\mathrm{Na}^{+}$ current density. (D) Representative $\mathrm{I}_{\mathrm{Na}}$ current traces from control and ricolinostat (ACY-1215) treated NMVMs showing an increase in peak $\mathrm{I}_{\mathrm{Na}}$ with $25 \mathrm{nM}$ ACY-1215. (E) Average $\mathrm{I}_{\mathrm{Na}}-\mathrm{V}_{\mathrm{m}}$ relationships for control $(n=17)$ and 10 and $25 \mathrm{nM}$ ricolinostat $(n=8,7)$ exhibit a concentration-dependent, but non-significant, increase in peak $\mathrm{I}_{\mathrm{Na}}$ density with class IIb HDAC6 inhibition.

\section{4. $V_{m}$-Dependence of $g_{N a}$ Activation and Inactivation}

Since both the activation and inactivation of $\mathrm{I}_{\mathrm{Na}}$ are dependent on the membrane potential $\left(\mathrm{V}_{\mathrm{m}}\right)$, we calculated the normalized $\mathrm{Na}^{+}$conductance $\left(\mathrm{g}_{\mathrm{Na}}\right)$ by dividing the average peak $\mathrm{I}_{\mathrm{Na}}$ by the difference between $V_{m}$ and the reversal potential $\left(E_{\text {rev }}\right)$ for $I_{N a}$, and then divided the $g_{N a}$ value for each $V_{m}$ by the maximum $\mathrm{g}_{\mathrm{Na}}$ value for each experiment. The $\mathrm{g}_{\mathrm{Na}}-\mathrm{V}_{\mathrm{m}}$ curves were fit with a Boltzmann function $g_{\mathrm{Na}}=\frac{\mathrm{g}_{\mathrm{Na}}^{\max }+\left(\mathrm{g}_{\mathrm{Na}}-\mathrm{g}_{\mathrm{Na}}^{\mathrm{max}}\right)}{\left[1+\exp \left(\left(\mathrm{V}_{\mathrm{m}}-\mathrm{V}_{1 / 2}\right) / \mathrm{dV}_{\mathrm{m}}\right)\right]}$ using Origin 8.6. A positive shift in the half activation voltage $\left(\mathrm{V}_{1 / 2}\right)$ of +2 to $+8 \mathrm{mV}$ was seen with trichostatin $\mathrm{A}$, vorinostat, and romidepsin in previous experiments [13]. A maximum positive shift in the $\mathrm{g}_{\mathrm{Na}}$ activation curve of $+6.4 \mathrm{mV}$ was observed with $100 \mathrm{nM}$ panobinostat (Figure 4A), again consistent with previous findings using pan-HDAC inhibitors. No shift in the activation threshold is apparent in the entinostat $\mathrm{I}-\mathrm{V}$ relationship and the $\mathrm{g}_{\mathrm{Na}}$ activation curve substantiates this observation (Figures $3 \mathrm{C}$ and $4 \mathrm{~B}$ ). In contrast to the other HDAC inhibitors, $25 \mathrm{nM}$ ricolinostat shifted the $\mathrm{I}_{\mathrm{Na}}$ activation threshold and the $\mathrm{g}_{\mathrm{Na}} \mathrm{V}_{1 / 2}$ by approximately $-4 \mathrm{mV}$ 
(Figures 3E and 4C). Previously, no shift in the $\mathrm{V}_{\mathrm{m}}$-dependent $\mathrm{g}_{\mathrm{Na}}$ inactivation curved was observed trichostatin A, vorinostat, or romidepsin [13]. The $\mathrm{g}_{\mathrm{Na}}$ inactivation protocol was not performed on panobinostat treated NMVMs, but the $\mathrm{V}_{1 / 2}$ for inactivation was shifted by $-3.5 \mathrm{mV}$ in the presence of $1 \mu \mathrm{M}$ entinostat. No shift in the $\mathrm{g}_{\mathrm{Na}}$ inactivation curve was observed with $25 \mathrm{nM}$ ricolinostat. To summarize, pan-HDAC inhibition by panobinostat shifted the $\mathrm{V}_{1 / 2}$ for activation, consistent with previous pan-HDACIs. Class I HDAC inhibition by $1 \mu \mathrm{M}$ entinostat had no effect on activation but shifted inactivation in the hyperpolarizing direction by 3-4 $\mathrm{mV}$ and HDAC6 inhibition with ricolinostat shifted activation approximately $4 \mathrm{mV}$ negative while having no effect on inactivation.
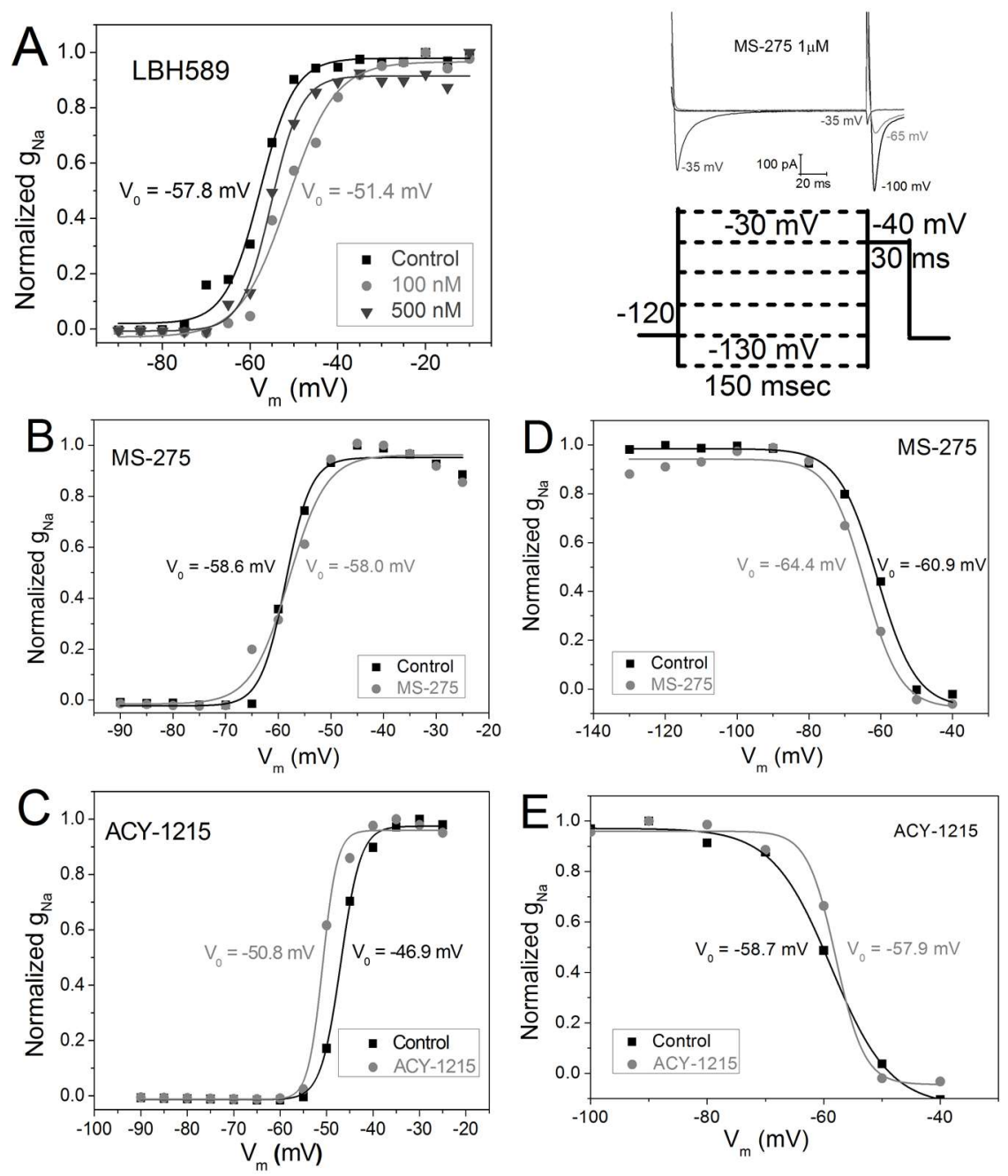

Figure 4. Effect of HDAC inhibition on $\mathrm{V}_{\mathrm{m}}$-dependent $\mathrm{I}_{\mathrm{Na}}$ activation and inactivation. (A) $\mathrm{V}_{\mathrm{m}}{ }^{-}$ dependent steady state $\mathrm{g}_{\mathrm{Na}}$ activation curves for the experiments shown in Figure 3B illustrating a slight positive shift in the half activation voltage $\left(\mathrm{V}_{1 / 2}\right)$ of $+2.5-6.4 \mathrm{mV}$ with pan-HDAC inhibition by panobinostat. (B) There was no shift in the $\mathrm{g}_{\mathrm{Na}}-\mathrm{V}_{\mathrm{m}}$ activation curve for class I selective HDAC inhibition by $1 \mu \mathrm{M}$ entinostat. (C) HDAC6 inhibition by $25 \mathrm{nM}$ ACY-1215 produced a $-4 \mathrm{mV}$ shift in the $\mathrm{g}_{\mathrm{Na}}-\mathrm{V}_{\mathrm{m}}$ activation curve. (D) $\mathrm{V}_{\mathrm{m}}$-dependent inactivation was examined using a prepulse protocol and $1 \mu \mathrm{M}$ entinostat caused a $-4 \mathrm{mV}$ shift in the $\mathrm{g}_{\mathrm{Na}}$ steady state inactivation $(n=9$ (control), 8). (E) Ricolinostat $(25 \mathrm{nM}, n=7)$ did not produce a shift in the $\mathrm{g}_{\mathrm{Na}} \mathrm{V}_{1 / 2}$ relative to control values $(n=6)$.

\subsection{Cardiac Late $I_{N a}$}

Increases in late or persistent $\mathrm{I}_{\mathrm{Na}}$ have been linked to cardiac arrhythmias and heart failure [27]. To examine the effects of HDAC inhibitors on late $\mathrm{I}_{\mathrm{Na}}$, we either measured the average $\mathrm{I}_{\mathrm{Na}}$ from 100 to 
$150 \mathrm{~ms}$ in response to the $\mathrm{I}_{\mathrm{Na}}$ activating $\mathrm{V}_{\mathrm{m}}$ steps or applied a slow $(40 \mathrm{msec} / \mathrm{mV}) \mathrm{V}_{\mathrm{m}}$ ramp from -80 to $+10 \mathrm{mV}$ from a holding potential of $-60 \mathrm{mV}$. Using the averaged inward whole cell current from 100 to $150 \mathrm{msec}$, no difference in late $\mathrm{I}_{\mathrm{Na}}$ was observed after overnight treatment with 100 or $500 \mathrm{nM}$ panobinostat compared to control $\mathrm{I}_{\mathrm{Na}}$ recordings, again consistent with our previous pan-HDAC inhibitor results (Figure 5C). Subsequently, we modified a voltage clamp ramp protocol designed to generate late $\mathrm{I}_{\mathrm{Na}} \mathrm{I}-\mathrm{V}$ relationships [28]. Late $\mathrm{I}_{\mathrm{Na}}$ currents recorded from control, $1 \mu \mathrm{M}$ entinostat, and $25 \mathrm{nM}$ ricolinostat treated NMVMs are shown in Figure 5A,B. Again, no increase in late $\mathrm{Na}^{+}$current density was observed with class I or IIb HDAC inhibition (Figure 5C).
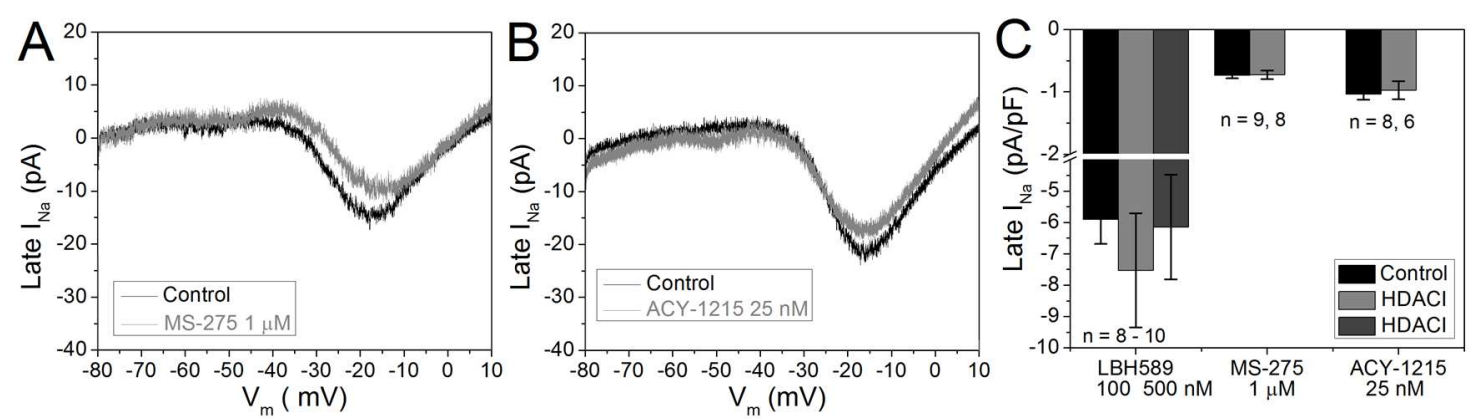

Figure 5. HDAC inhibition does not increase late $\mathrm{I}_{\mathrm{Na}}$. (A) Whole cell late $\mathrm{I}_{\mathrm{Na}}$ currents generated by a $90 \mathrm{mV}, 3.6 \mathrm{~s} \mathrm{~V}_{\mathrm{m}}$ ramp from -80 to $+10 \mathrm{mV}$ in a control NMVM and a NMVM treated with $1 \mu \mathrm{M}$ entinostat for 18-24 h. (B) Late $\mathrm{I}_{\mathrm{Na}}$ currents recorded from a control NMVM and a NMVM treated with $25 \mathrm{nM}$ ricolinostat overnight. (C) Averaged late $\mathrm{I}_{\mathrm{Na}}$ current density (pA)/pF) from 6-10 NMVMs treated with panobinostat, entinostat, or ricolinostat illustrating no increase in late $\mathrm{I}_{\mathrm{Na}}$ relative to untreated NMVMs after 18-24 h exposure to pan- or class-selective HDAC inhibitors. Late $\mathrm{I}_{\mathrm{Na}}$ was measured as the average steady state $\mathrm{I}_{\mathrm{Na}}$ current from 100 to $150 \mathrm{msec}$ in control and panobinostat treated NMVMs in response to activating $V_{m}$ pulses (Figure $3 \mathrm{~A}, \mathrm{~B}$ ).

\section{6. $\mathrm{C} x 43$ and $\mathrm{Na} a_{V} 1.5$ Expression}

Because panobinostat caused a concentration-dependent reduction in $\mathrm{I}_{\mathrm{Na}}$ and $\mathrm{g}_{\mathrm{j}}$, we performed Western blot analyses on NMVMs to determine if there were any alterations in cardiac $\mathrm{Na}_{V} 1.5$ and $\mathrm{Cx} 43$ protein expression level induced by pan-HDAC inhibition. Protein expression analysis of cultured NMVMs revealed a concentration-dependent decrease of both $\mathrm{Na}_{\mathrm{V}} 1.5$ and $\mathrm{Cx} 43$ with panobinostat treatment $(p<0.05, n=3)$, whereas no changes were observed with entinostat and ricolinostat (Figure 6). Acetyl- $\alpha$-tubulin and acetyl-histone 3 were used as cytoplasmic and nuclear acetylation markers respectively. $\alpha$-tubulin was used as a loading control. 

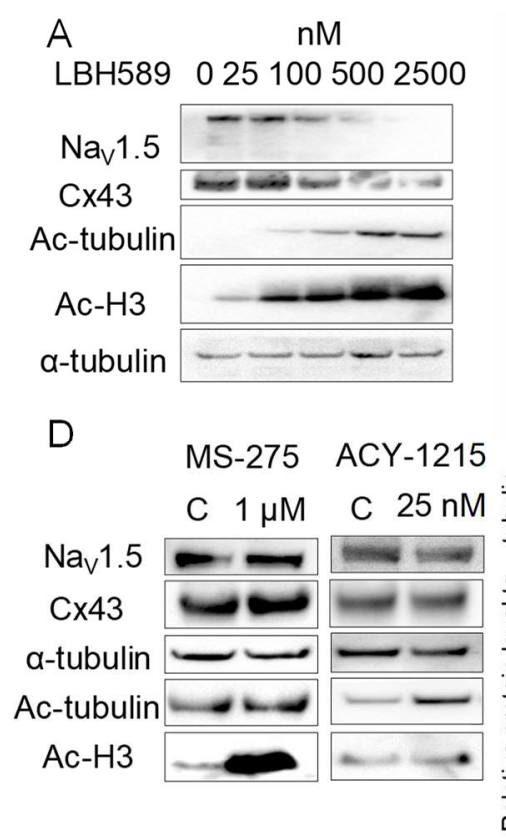
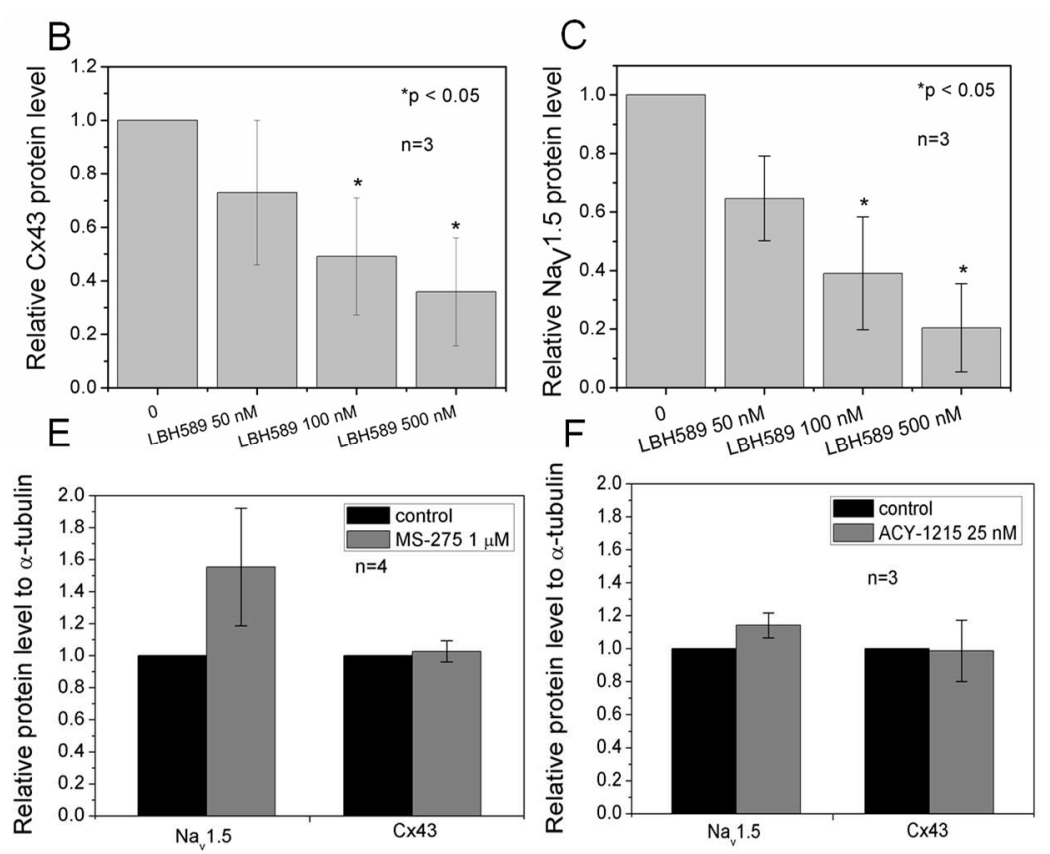

Figure 6. Changes in cardiac $\mathrm{C} \times 43$ and $\mathrm{Na}_{\mathrm{V}} 1.5$ protein levels by panobinostat, entinostat and ricolinostat. (A) Representative Western blot of lysed NMVMs treated with 0, 25, 100, 500, and $2500 \mathrm{nM}$ panobinostat for $24 \mathrm{~h}$. Ac-tubulin is acetylated $\alpha$-tubulin, Ac-H3 is acetylated histone 3, and $\alpha$-tubulin was used as a loading control. (B) Densitometry scans of Cx43 Western blots $(n=3)$ to quantify the reduction in Cx43 protein levels with increasing concentrations of panobinostat $\left({ }^{*} p<0.05\right)$. (C) Densitometry scans of $\mathrm{Na}_{\mathrm{V}} 1.5$ Western blots $(n=3)$ quantifying the statistically significant decrease in Nav1.5 protein levels with higher concentrations of panobinostat $(* p<0.05)$. (D) A representative Western blot of lysed ventricular myocytes treated with $1 \mu \mathrm{M}$ entinostat (MS-275) or $25 \mathrm{nM}$ ricolinostat for $24 \mathrm{~h}$. Note that MS-275 only increased the Ac-H3 signal while ACY-1215 only increased the Ac- $\alpha$-tubulin signal, consistent with their class I and HDAC6 inhibitory activities. (E) Densitometry scans of $1 \mu \mathrm{M}$ entinostat Western blots $(n=4)$ illustrating no significant changes in $\mathrm{Cx} 43$ or $\mathrm{Na}_{\mathrm{V}} 1.5$ protein levels with entinostat, a class I HDAC-selective inhibitor. (F) Densitometry scans of $25 \mathrm{nM}$ ricolinostat Western blots $(n=3)$ illustrating no significant changes in $\mathrm{Cx} 43$ or $\mathrm{Na}_{\mathrm{V}} 1.5$ protein levels with ricolinostat.

\section{Discussion}

The HDAC inhibitors have tremendous potential in the field of cancer pharmacology due to their involvement in key regulatory and gene expression pathways [29,30]. To date, four non-selective HDAC inhibitors, vorinostat (VOR, suberoylanilide hydroxamic acid (SAHA), Zolinza ${ }^{\mathrm{TM}}, 2006$ ), romidepsin (FK228, depsipeptide, Istodax ${ }^{\mathrm{TM}}$, 2009), belinostat (PXD101, Beleodaq ${ }^{\mathrm{TM}}$, 2014) and panobinostat (LBH589, Farydak ${ }^{\mathrm{TM}}$, 2015), have been approved by FDA for chemotherapy of cutaneous/peripheral T-cell lymphoma or multiple myeloma. Furthermore, hundreds of HDAC inhibitors are undergoing clinical trials (www.clinicaltrials.gov). However, HDAC inhibitor-related severe cardiotoxic side effects, especially QT interval prolongation, ventricular arrhythmia and unexpected sudden cardiac death, necessitated clinical trial termination or dose readjustments of numerous promising non-selective HDAC inhibitors [4-7]. In addition, panobinostat, the most potent pan-HDAC inhibitor, carries a black box warning for severe cardiac abnormalities on its prescription label [31]. Notably, currently approved HDAC inhibitors can non-selectively inhibit all 11 zinc-dependent isoforms in this family [32]. Based on their sequence homology to Saccharomyces cerevisiae HDACs and their cellular location, those targeted HDACs can be divided into four classes. Class I HDACs (HDAC1, 2, 3 and 8) are homologous proteins of yeast that reduce potassium-dependent $3(\mathrm{Rpd} 3)$. These HDACs are mainly present in the nucleus and are ubiquitously expressed. Class II HDACs share sequence homology to yeast histone deacetylase 
1 (Hda1). They are further divided into two groups based on their subcellular localization, with class IIa (HDAC4, 5, 7 and 9) shuttle between the nucleus and cytoplasm, while class Ilb (HDAC6 and 10) is located in the cytoplasm. HDAC11 is the only class IV HDAC that shares sequence similarity with Rpd3 and Hda1 and has not been well studied.

HDACs are tissue specific. For example, class I HDACs are ubiquitous, while class II HDACs are only expressed in specific tissues such as heart, kidney, and brain. Furthermore, different HDACs are overexpressed in different cancers. It is worth noting that the different classes of HDAC have distinct regulatory mechanisms and play distinct roles on cardiac activities. For example, class IIa HDACs are regulated by the calcium/calmodulin-dependent protein kinase II (CaMKII) pathway and inhibits MEF (myoblast-enhancing factor)-associated cardiac hypertrophy and is therefore used as a protective agent for cardiac hypertrophy [33]. Class I HDACs play a "pro-hypertrophic" role in heart and inhibition of this HDAC class attenuates cardiac hypertrophy through tuberous sclerosis complex 2-dependent mTOR repression [34]. Based on these facts, it has been hypothesized that class-selective HDACs present a new strategy for the treatment of cancer, with the goal of minimizing cardiotoxicity $[8,35]$. Encouragingly, the development of the Class I HDAC inhibitor entinostat has enabled this goal. Entinostat combined with exemestane increased overall survival and progression-free survival in patients with advanced hormone receptor (HR)-positive breast cancer without adverse cardiac toxicity events $[7,11]$. But the mechanisms for the reduced arrhythmogenic cardiotoxicities observed with pan-HDAC inhibitors remains essentially unknown.

Blockade of human ether-a-go-go (hERG) channels and the subsequent inhibition of the rapidly activating delayed rectifier potassium current $\left(\mathrm{I}_{\mathrm{Kr}}\right)$ is responsible for more than $95 \%$ of acquired or drug-induced Long QT syndromes and led to withdrawal of multiple drugs including terfenadine (Seldane) [36]. Therefore, hERG-dependent assays were required for screening new therapeutic drugs according to the preclinical testing recommendations of the ICH S7A guidelines. All four FDA approved HDAC inhibitors, with the possible exception of panobinostat, failed to show significant hERG blockade activity, implying that other mechanisms are involved in HDAC inhibitor-related cardiotoxicities $[18,37,38]$. In addition, the three HDAC inhibitors in this study showed insignificant effects on steady state and transient outward $\mathrm{K}^{+}$currents of NMVM cells (Supplementary Figures S1 and S2). Thus, we hypothesize that hERG is not responsible for cardiac side effects of HDAC inhibitors and, hence, we focused our studies on other major cardiac ionic currents which can be altered by HDAC inhibition.

After examining four pan-HDAC inhibitors including panobinostat, we have consistently observed concomitant reductions in gap junction coupling and peak $\mathrm{I}_{\mathrm{Na}}$, without alterations in $\mathrm{I}_{\mathrm{Na} \text {, Late }}$ and a slight shift of 2-3 mV during activation with no change in inactivation of $\mathrm{I}_{\mathrm{Na}}[13,14]$. With the phase 3 clinical trial class I HDAC inhibitor, entinostat, we observed no change in ventricular $g_{j}$, peak $\mathrm{I}_{\mathrm{Na}}$ density, or the $\mathrm{V}_{1 / 2}$ for $\mathrm{V}_{\mathrm{m}}$-dependent activation and inactivation at the class-selective concentration of $1 \mu \mathrm{M}$. The lack of these effects may help explain the safer record of entinostat pertaining to cardiotoxicity, especially considering that this concentration is still more than three times the therapeutic dose used in clinical trials [7,18]. The phase 1-2 clinical trial class IIb HDAC inhibitor, ricolinostat, also had minor effects on ventricular $\mathrm{g}_{\mathrm{j}}$ and $\mathrm{I}_{\mathrm{Na}}$ electrophysiological properties. A $1 \times$ $\mathrm{IC}_{50}$ dose of ricolinostat produced a modest increase in $\mathrm{g}_{\mathrm{j}}$ while a $2.5 \times \mathrm{IC}_{50}$ dose produced a similar decrease in $\mathrm{g}_{\mathrm{j}}$. This trend (induction at lower concentration and reduction at higher concentration) was also observed with the prototype HDAC6 inhibitor, tubacin, although none of the $g_{j}$ changes were significant. It is worth noting that $1 \times \mathrm{IC}_{50}$ dose of ricolinostat is still four times higher than the maximum dose used in clinical trials. Thus, we conclude that therapeutic doses of ricolinostat are unlikely to cause any significant changes in gap junction coupling. In addition, the differential effects of pan-, class 1-selective, and class IIb-selective HDAC inhibitors implies that different classes of HDACs likely have different effects on Cx43 expression and function. Furthermore, the combined effects of sodium butyrate and tubacin suggest that inhibiting multiple classes of HDACs accounts for some of the adverse cardiac side effects attributable to pan-HDAC inhibitors. 
HDAC6 is preferentially inhibited by ricolinostat at concentrations applied. One of its deacetylated substrates is Hsp90, the $90 \mathrm{kDa}$ heat shock protein $[39,40]$. Hsp90 is an ATP-dependent chaperone that helps stabilize many proteins. Hsp90 has been shown to serve two distinct roles relevant to $\mathrm{Cx} 43$ expression and function. Hsp90 mediates the mitochondrial translocation of $\mathrm{Cx} 43$ and increases the mitochondrial membrane expression of Cx43 at the expense of cell surface expression of Cx43 [41]. $\mathrm{Hsp} 90$ is also part of a Cx43 promotor P2 region protein complex and is involved in Ras-mediated Cx43 upregulation [42]. Thus, partial or complete inhibition of HDAC6 deacetylase activity by ricolinostat will result in increased acetylation of Hsp90 and promote the disparate actions of Hsp90 on Cx43 expression and localization. In addition, microtubules are responsible for $\mathrm{C} \times 43$ forward trafficking and consist of $\alpha$-tubulin and $\beta$-tubulin [43]. $\alpha$-tubulin is another known substrate for HDAC6. siRNA mediated knockdown of HDAC6 or non-selective HDAC inhibition induces tubulin hyper-acetylation, which was accompanied by aggregate formation in cardiomyopathy mice hearts [44]. However, a recent structural analysis revealed that the lysine residue K40 of $\alpha$-tubulin targeted by HDAC6 deacetylation resides on the inner face of microtubules, and that $\mathrm{K} 40$ acetylation status had no effect on the ultrastructure of microtubules [45].

Entinostat preferentially inhibits HDAC1 by two-fold over HDAC3 and 10-100-fold over other HDACs. Two laboratories, including ours, have demonstrated that HDAC1 is bound to the Cx43 promoter region [14,46]. Loss of HDAC1 drastically increases gene silencing, including GJA1, resulting in decreased Cx43 mRNA levels [47]. Therefore, HDAC inhibitors capable of HDAC1 inhibition, e.g., pan-HDAC and class I-selective HDAC inhibitors, should cause a reduction of Cx43 expression. We did not observe any change in $\mathrm{Cx} 43$ protein level with $1 \mu \mathrm{M}$ entinostat, which may result from the compensatory deacetylase effects of class IIa HDACs. HDAC4 and HDAC5 colocalize with Cx43 and a class IIa HDAC inhibitor MC1568 produced Cx43 hyperacetylation and dissociation from intercalated disk gap junctions in ventricular cardiomyocytes [48]. This may also explain the observation that non-selective inhibition of class I and II HDACs by pan-HDAC inhibitors significantly reduces Cx43 expression, but not by a class I HDAC inhibitor.

Finally, we observed a moderate, but not significant, increase in peak $\mathrm{I}_{\mathrm{Na}}$ at twice the HDAC6 $\mathrm{IC}_{50}$ concentration of ricolinostat. The cardiac sodium channel Nav1.5 protein is acetylated and acetylation of $\mathrm{K}$ on the III-IV linker reduces its forward trafficking to the cell surface, thus reducing cardiac $\mathrm{Na}^{+}$current density $[13,49]$. The HDACs associated with $\mathrm{Na}_{\mathrm{V}} 1.5$ are not yet identified, but our results suggest that HDAC6 activity may influence the surface expression and stability of the $\mathrm{Na}_{\mathrm{V}} 1.5$ protein complex either by directly modulating the acetylation of $\mathrm{Na}_{\mathrm{V}} 1.5$ or indirectly by modulating the acetylation, phosphorylation, or ubiquitination of $\mathrm{Na}_{\mathrm{V}} 1.5$ interacting proteins. Mutations and expression of key $\mathrm{Na}_{\mathrm{V}} 1.5$ interacting proteins like $\alpha 1$-syntrophin, calveolin-3, plakophilin-2, and others are known to influence the expression and function of the $\mathrm{Na}_{\mathrm{V}} 1.5$ channel and are linked to increased risk for cardiac arrhythmias and sudden cardiac death [16]. Overall, the class-selective HDAC inhibitors exhibit no or moderate effects on Cx43-mediated gap junction communication and cardiac sodium current density, unlike pan-HDAC inhibitors, which may help explain their lack of cardiotoxicity and improved safety profile.

\section{Material and Methods}

\subsection{Cell Culture}

Neonatal mice born from an inbred C57BL/6 mouse colony were anesthetized using isoflurane and the hearts were excised in accordance with procedures approved by the SUNY Upstate Medical University Institutional Animal Care and Use Committee (IACUC) \# 263 on 15 March 2017. The excised hearts were separated into atria and ventricles and exposed to collagenase solution for digestion. The dissociated cells were pre-plated for $30 \mathrm{~min}$ to reduce fibroblast content by differential adhesion and the supernatant was collected, centrifuged and re-suspended in $1 \mathrm{~mL} /$ heart of M199/10\% FBS culture media. The primary cells were plated into 96-well plates for HDAC activity assays, $35 \mathrm{~mm}$ 
culture dishes for patch clamp electrophysiology, or $60 \mathrm{~mm}$ culture dishes and homogenized after 3 days for Western blots.

\subsection{HDAC Inhibitors}

Panobinostat (LBH589), entinostat (MS275) and ricolinostat (ACY-1215) were purchased from Selleck Chemicals (Houston, TX, USA), dissolved in DMSO, and stored at $-20{ }^{\circ} \mathrm{C}$. The $100-\mathrm{mM}$ DMSO solutions of LBH589, MS-275 and ACY-1215 were diluted to the desired experimental test concentrations in M199 and applied to NMVM overnight for 18-24 h before experimental procedures. Final DMSO levels were $<0.005 \%$ (vol/vol).

\subsection{HDAC Activity Assay}

Aliquots of $2 \times 10^{5}$ ventricular myocytes per well (96-well plate) were grown in $200 \mu \mathrm{L}$ of $200 \mu \mathrm{M}$ bromodeoxyuridine (BrDU)/M199, exchanged daily. Cell densities were counted with a hemocytometer and seeded into the wells. Wells were incubated with 2000 pmoles of the acetylated Fluor-de-Lys ${ }^{\circledR}$ substrate for $8 \mathrm{~h}$ during HDAC inhibition $[13,14]$. Cells were incubated with varying doses of HDAC inhibitor, panobinostat, for $24 \mathrm{~h}$. Protocols for HDAC activity assay were developed according to manufacturer's directions (Cat. \# BML-AK500, Enzo Life Sciences, Farmingdale, NY, USA) and background subtracted relative fluorescence unit (RFU) counts were acquired with a BIO-TEK Synergy 2 plate reader ( $360 \mathrm{~nm}$ excitation, $460 \mathrm{~nm}$ emission).

\subsection{Dual Whole Cell Patch Clamping}

Gap junction currents $\left(\mathrm{I}_{\mathrm{j}}\right)$ were recorded in the dual whole cell configuration according to previously published methods [50]. Upon establishing a dual whole cell patch, $\mathrm{I}_{\mathrm{j}}$ was recorded using a $30 \mathrm{~s}, 20 \mathrm{mV}$ trans-junctional voltage protocol. All dual whole cell current recordings were low-pass filtered at $500 \mathrm{~Hz}$ and digitized at $2 \mathrm{KHz}$ using pClamp 8.2 and graphical analysis performed using Origin 7.5 or 8.6 software as previously described [14].

\subsection{Whole Cell Patch Clamping}

Single whole cell patch electrode voltage clamp experiments were performed on neonatal mouse ventricular myocytes (NMVMs) using conventional procedures with an Axon Instruments Axopatch 1D or 200B patch clamp amplifier, Digidata 1320A or 1440 A/D converter, and pClamp8.2 or 10.1 software (Molecular Devices, San Jose, CA, USA). Transient (peak) and steady state outward potassium ( $\mathrm{I}_{\mathrm{K}, \mathrm{to}}$ and $\left.\mathrm{I}_{\mathrm{K}, \mathrm{s}}\right)$ currents were recorded during $1 \mathrm{sec}$ voltage steps from a holding potential $\left(\mathrm{V}_{\mathrm{h}}\right)$ of -100 to $+60 \mathrm{mV}$ in $10 \mathrm{mV}$ increments. Voltage-gated sodium currents $\left(\mathrm{I}_{\mathrm{Na}}\right)$ were elicited from a $\mathrm{V}_{\mathrm{h}}$ of $-120 \mathrm{mV}$ during voltage steps from -90 to $+50 \mathrm{mV}$ in $5 \mathrm{mV}$ increments for $150 \mathrm{~ms}$ using reduced $\mathrm{NaCl}$ solutions. For the $\mathrm{I}_{\mathrm{Na}}$ inactivation protocol, $\mathrm{V}$ was $-120 \mathrm{mV}$ and the prepulse voltage increased from -130 to $-30 \mathrm{mV}$ in $+5-\mathrm{mV}$ increments for $150 \mathrm{~ms}$ followed by a 30-ms activation step to $-40 \mathrm{mV}$ [13]. Late $\mathrm{I}_{\mathrm{Na}}$ protocol was measured as the average current from 100 to $150 \mathrm{~ms}$ of the activating voltage steps or were recorded during a ramp from -80 to $+10 \mathrm{mV}$ in $0.1 \mathrm{mV} / 4 \mathrm{~ms}$ steps from a $\mathrm{V}_{\mathrm{h}}$ of $-60 \mathrm{mV}[13,28]$.

\subsection{Western Blot}

Ventricular myocytes were cultured at high density in $35 \mathrm{~mm}$ culture dishes for four days in $3 \mathrm{~mL}$ of BrDU/M199 media, harvested, and lysed with 1\% Triton X-100 extraction buffer (50 mM Tris pH 8.0, $150 \mathrm{mM} \mathrm{NaCl}, 0.02 \%$ Sodium azide, $1.0 \mathrm{mM}$ PMSF, $1 \mu \mathrm{g} / \mathrm{mL}$ Aprotinin, $1 \%$ Triton X-100, $1 \mathrm{mM}$ $\mathrm{Na}_{3} \mathrm{VO}_{4}, 50 \mathrm{mM} \mathrm{NaF}$ ) with protease inhibitors (Roche Life Sciences, Branford, CT, USA). One dish from each primary culture served as a control sample and a second dish was treated with panobinostat or entinostat for $24 \mathrm{~h}$ prior to harvesting. Sonicated samples (three $30 \mathrm{sec}$ pulses) were incubated on ice for $30 \mathrm{~min}$, centrifuged at $14,000 \mathrm{rpm}\left(10 \mathrm{~min}\right.$ at $\left.4{ }^{\circ} \mathrm{C}\right)$, transferred to new tubes, and protein concentrations were measured using the coomassie blue protein assay (Bio-Rad, Hercules, CA, USA). 
Total protein/sample was heated $\left(55^{\circ} \mathrm{C}\right)$ and loaded onto an SDS-PAGE gel and electrophoresed for $90 \mathrm{~min}$ at $110 \mathrm{~V}$ in $4 \times$ Nupage sampling buffer and $10 \times$ Nupage reducing buffer (Bio-Rad). The protein gels were transferred onto polyvinylidine difluoride (PVDF) membranes for $90 \mathrm{~min}$ at $4{ }^{\circ} \mathrm{C}(110 \mathrm{~V})$, blocked with $5 \%$ nonfat milk for $1 \mathrm{~h}$ at room temperature, and incubated overnight at $4{ }^{\circ} \mathrm{C}$ with primary antibodies against $\mathrm{Cx} 43, \mathrm{Na} \mathrm{v}_{\mathrm{V}} 1.5$ or $\alpha$-tubulin in PBS-T with $5 \%$ nonfat milk. Acetylated $\alpha$-tubulin and acetylated $\mathrm{H} 3$ were used as cytoplasmic and nuclear markers for acetylation. The membranes were washed $5 \mathrm{~min} \times 4$ with PBS-T, incubated with HRP labeled secondary antibody (1:5000) at room temperature in PBS-T with $5 \%$ nonfat milk for $30 \mathrm{~min}$, washed again $5 \mathrm{~min} \times 4$ with PBS-T, and developed using the ECL ${ }^{\mathrm{TM}}$ Western Blot Detection Reagents (Bio-Rad). The image was detected using the Biorad imager. The density of the bands was quantified using ImageJ.

Primary antibodies used in this study include rabbit anti-Cx43 (AB1728, Merck Millipore, Billerica, MA, USA), mouse anti-Cx43 (AB1727, Merck Millipore), mouse anti- $\alpha$-tubulin (\# T5168, Sigma-Aldrich, St. Louis, MO, USA), rabbit anti-acetylated H3 (\# 06-599, Merck Millipore), rabbit anti-acetylated- $\alpha$-tubulin (BML-SA452-0100, Enzo Life Sciences, Farmingdale, NY, USA) and rabbit anti-Nav1.5 (\# ACC-001, Alomone Labs, Jerusalem, Israel).

\subsection{Statistics}

Averaged values are presented as the Mean \pm SEM. Statistical analyses were performed with the Normality and one-way ANOVA tests using the Bonferroni method in Origin 8.6. Data with $p<0.05$ were considered significant.

\section{Conclusions}

This study demonstrates for the first time that class-selective HDAC inhibitors, entinostat and ricolinostat, produce no or moderate effects on functional electrical coupling and cardiac sodium currents in normal mammalian ventricular myocardium, which distinguished from pan-HDAC inhibitors. Therefore, class-selective HDAC inhibitors are likely to benefit broad patients with improved cardiac profile in clinical practice.

Supplementary Materials: Supplementary materials can be found at http:/ / www.mdpi.com/1422-0067/19/8/ 2288/s1.

Author Contributions: Conceptualization and research design, D.P., X.Z., and R.V.; Experiments, D.P., Q.X. and X.Z.; Data Analysis, X.Z., D.P., Q.X., and R.V.; Interpretation, X.Z., D.P., and R.V.; Figure preparation; X.Z, D.P., and R.V.; Writing-Original draft preparation, X.Z. and R.D.V; Manuscript Editing and Revising, X.Z, D.P., and R.V., Manuscript Approval-final version, X.Z., D.P., Q.X., and R.V.

Funding: This project was supported by National Institutes of Health grant HL-042220, National American Heart Association Grant-in-Aid 17GRNT33710031, and Central New York Community Joseph C Georg Fund grant to R.V.

Conflicts of Interest: The authors have no conflict of interest to declare.

\section{References}

1. Peng, L.; Seto, E. Deacetylation of nonhistone proteins by HDACs and the implications in cancer. Handb. Exp. Pharmacol. 2011, 206, 39-56. [PubMed]

2. Gryder, B.E.; Sodji, Q.H.; Oyelere, A.K. Targeted cancer therapy: Giving histone deacetylase inhibitors all they need to succeed. Future Med. Chem. 2012, 4, 505-524. [CrossRef] [PubMed]

3. Ito, A.; Kawaguchi, Y.; Lai, C.H.; Kovacs, J.J; Higashimoto, Y.; Appella, E.; Yao, T.P. MDM2-HDAC1-mediated deacetylation of p53 is required for its degradation. EMBO J. 2002, 21, 6236-6245. [CrossRef] [PubMed]

4. Lynch, D.R., Jr.; Washam, J.B.; Newby, L.K. QT interval prolongation and torsades de pointes in a patient undergoing treatment with vorinostat: A case report and review of the literature. Cardiol. J. 2012, 19, 434-438. [CrossRef] [PubMed] 
5. Kelly, W.K.; Richon, V.M.; O'Connor, O.; Curley, T.; MacGregor-Curtelli, B.; Tong, W.; Klang, M.; Schwartz, L.; Richardson, S.; Rosa, E.; et al. Phase I clinical trial of histone deacetylase inhibitor: Suberoylanilide hydroxamic acid administered intravenously. Clin. Cancer Res. 2003, 9, 3578-3588. [PubMed]

6. Shah, M.H.; Binkley, P.; Chan, K.; Xiao, J.; Arbogast, D.; Collamore, M.; Farra, Y.; Young, D.; Grever, M. Cardiotoxicity of histone deacetylase inhibitor depsipeptide in patients with metastatic neuroendocrine tumors. Clin. Cancer Res. 2006, 12, 3997-4003. [CrossRef] [PubMed]

7. Schiattarella, G.G.; Sannino, A.; Toscano, E.; Cattaneo, F.; Trimarco, B.; Esposito, G.; Perrino, C. Cardiovascular effects of histone deacetylase inhibitors epigenetic therapies: Systematic review of 62 studies and new hypotheses for future research. Int. J. Cardiol. 2016, 219, 396-403. [CrossRef] [PubMed]

8. Micelli, C.; Rastelli, G. Histone deacetylases: Structural determinants of inhibitor selectivity. Drug Disc. Today 2015, 20, 718-735. [CrossRef] [PubMed]

9. Ryan, Q.C.; Headlee, D.; Acharya, M.; Sparreboom, A.; Trepel, J.B.; Ye, J.; Figg, W.D.; Hwang, K.; Chung, E.J.; Murgo, A.; et al. Phase I and pharmacokinetic study of MS-275, a histone deacetylase inhibitor, in patients with advanced and refractory solid tumors or lymphoma. J. Clin. Oncol. 2005, 23, 3912-3922. [CrossRef] [PubMed]

10. Vogl, D.T.; Raje, N.; Jagannath, S.; Richardson, P.; Hari, P.; Orlowski, R.; Supko, J.G.; Tamang, D.; Yang, M.; Jones, S.S.; et al. Ricolinostat, the first selective histone deacetylase 6 inhibitor, in combination with bortezomib and dexamethasone for relapsed or refractory multiple myeloma. Clin. Cancer Res. 2017, 23, 3307-3315. [CrossRef] [PubMed]

11. Yardley, D.A.; Ismail-Khan, R.R.; Klein, P.M. PD01-04: Entinostat, a novel histone deacetylase inhibitor, added to exemestane improves PFS in advanced breast cancer in a randomized, phase II, double-blind study. Cancer Res. 2011, 71, PD01-PD04. [CrossRef]

12. Ruiz, R.; Raez, L.E.; Rolfo, C. Entinostat (SNDX-275) for the treatment of non-small cell lung cancer. Expert. Opin. Investig. Drugs 2015, 24, 1101-1109. [CrossRef] [PubMed]

13. Xu, Q.; Patel, D.; Zhang, X.; Veenstra, R.D. Changes in cardiac Nav 1.5 expression, function, and acetylation by pan-histone deacetylase inhibitors. Am. J. Physiol. Hear. Circ. Physiol. 2016, 311, H1139-H1149. [CrossRef] [PubMed]

14. Xu, Q.; Lin, X.; Andrews, L.; Patel, D.; Lampe, P.D.; Veenstra, R.D. Histone deacetylase inhibition reduces cardiac connexin43 expression and gap junction communication. Front. Pharmacol. 2013, 4, 44. [CrossRef] [PubMed]

15. Fontes, M.S.C.; van Veen, T.A.B.; de Bakker, J.M.T.; van Rijen, H.V.M. Functional consequences of abnormal Cx43 expression in the heart. Biochim. Biophys. Acta Biomembr. 2012, 1818, 2020-2029. [CrossRef] [PubMed]

16. Abriel, H.; Rougier, J.S.; Jalife, J. Ion channel macromolecular complexes in cardiomyocytes: Roles in sudden cardiac death. Circ. Res. 2015, 116, 1971-1988. [CrossRef] [PubMed]

17. Ortiz-Bonnin, B.; Rinné, S.; Moss, R.; Streit, A.K.; Scharf, M.; Richter, K.; Stöber, A.; Pfeufer, A.; Seemann, G.; Kääb, S.; et al. Electrophysiological characterization of a large set of novel variants in the SCN5A-gene: Identification of novel LQTS3 and BrS mutations. Pflügers. Arch Eur. J. Physiol. 2016, 468, 1375-1387. [CrossRef] [PubMed]

18. Kopljar, I.; Gallacher, D.J.; de Bondt, A.; Cougnaud, L.; Vlaminckx, E.; van den Wyngaert, I.; Lu, H.R. Functional and Transcriptional Characterization of Histone Deacetylase Inhibitor-Mediated Cardiac Adverse Effects in Human Induced Pluripotent Stem Cell-Derived Cardiomyocytes. Stem Cells Transl. Med. 2016, 5, 602-612. [CrossRef] [PubMed]

19. Beckers, T.; Burkhardt, C.; Wieland, H.; Gimmnich, P.; Ciossek, T.; Maier, T.; Sanders, K. Distinct pharmacological properties of second generation HDAC inhibitors with the benzamide or hydroxamate head group. Int. J. Cancer 2007, 121, 1138-1148. [CrossRef] [PubMed]

20. Santo, L.; Hideshima, T.; Kung, A.L.; Tseng, J.C.; Tamang, D.; Yang, M.; Jarpe, M.; van Duzer, J.H.; Mazitschek, R.; Ogier, W.C.; et al. Preclinical activity, pharmacodynamic, and pharmacokinetic properties of a selective HDAC6 inhibitor, ACY-1215, in combination with bortezomib in multiple myeloma. Blood 2012, 119, 2579-2589. [CrossRef] [PubMed]

21. Haggarty, S.J.; Koeller, K.M.; Wong, J.C.; Grozinger, C.M.; Schreiber, S.L. Domain-selective small-molecule inhibitor of histone deacetylase 6 (HDAC6)-mediated tubulin deacetylation. Proc. Natl. Acad. Sci. USA 2003, 100, 4389-4394. [CrossRef] [PubMed] 
22. Rasheed, W.K.; Johnstone, R.W.; Prince, H.M. Histone deacetylase inhibitors in cancer therapy. Expert. Opin. Investig. Drugs 2007, 16, 659-678. [CrossRef] [PubMed]

23. Khan, N.; Jeffers, M.; Kumar, S.; Hackett, C.; Boldog, F.; Khramtsov, N.; Qian, X.; Mills, E.; Berghs, S.C.; Carey, N.; et al. Determination of the class and isoform selectivity of small-molecule histone deacetylase inhibitors. Biochem. J. 2008, 409, 581-589. [CrossRef] [PubMed]

24. Asklund, T.; Appelskog, I.B.; Ammerpohl, O.; Ekström, T.J.; Almqvist, P.M. Histone deacetylase inhibitor 4-phenylbutyrate modulates glial fibrillary acidic protein and connexin 43 expression, and enhances gap-junction communication, in human glioblastoma cells. Eur. J. Cancer 2004, 40, 1073-1081. [CrossRef] [PubMed]

25. Kaufman, J.; Gordon, C.; Bergamaschi, R.; Wang, H.Z.; Cohen, I.S.; Valiunas, V.; Brink, P.R. The effects of the histone deacetylase inhibitor 4-phenylbutyrate on gap junction conductance and permeability. Front. Pharmacol. 2013, 4, 111. [CrossRef] [PubMed]

26. Bradner, J.E.; West, N.; Grachan, M.L.; Greenberg, E.F.; Haggarty, S.J.; Warnow, T.; Mazitschek, R. Chemical phylogenetics of histone deacetylases. Nat. Chem. Biol. 2010, 6, 238-243. [CrossRef] [PubMed]

27. Makielski, J.C. Late sodium current: A mechanism for angina, heart failure, and arrhythmia. Trends Cardiovasc. Med. 2016, 26, 115-122. [CrossRef] [PubMed]

28. Xie, R.G.; Zheng, D.W.; Xing, J.L.; Zhang, X.J.; Song, Y.; Xie, Y.B.; Kuang, F.; Dong, H.; You, S.W.; Xu, H.; et al. Blockade of persistent sodium currents contributes to the riluzole-induced inhibition of spontaneous activity and oscillations in injured DRG neurons. PLoS ONE 2011, 6, e18681. [CrossRef] [PubMed]

29. Bose, P.; Dai, Y.; Grant, S. Histone deacetylase inhibitor (HDACI) mechanisms of action: Emerging insights. Pharmacol. Ther. 2014, 143, 323-336. [CrossRef] [PubMed]

30. Newbold, A.; Falkenberg, K.J.; Prince, H.M.; Johnstone, R.W. How do tumor cells respond to HDAC inhibition? FEBS J. 2016, 283, 4032-4046. [CrossRef] [PubMed]

31. FDA Reference ID: 3699607. Available online: https://www.accessdata.fda.gov/drugsatfda_docs/label/ 2015/205353s000lbl.pdf (accessed on 3 August 2018).

32. Hojayev, B.; Hill, J.A. HDACs and hypertrophy, kinases and cancer. Circulation 2011, 123, $2341-2343$. [CrossRef] [PubMed]

33. Backs, J.; Song, K.; Bezprozvannaya, S.; Chang, S.; Olson, E.N. CaM kinase II selectively signals to histone deacetylase 4 during cardiomyocyte hypertrophy. J. Clin. Investig. 2006, 116, 1853-1864. [CrossRef] [PubMed]

34. Morales, C.R.; Li, D.L.; Pedrozo, Z.; May, H.I.; Jiang, N.; Kyrychenko, V.; Cho, G.W.; Kim, S.Y.; Wang, Z.V.; Rotter, D.; et al. Inhibition of class I histone deacetylases blunts cardiac hypertrophy through TSC2-dependent mTOR repression. Sci. Signal. 2016, 9. [CrossRef] [PubMed]

35. Bieliauskas, A.V.; Pflum, M.K.H. Isoform-selective histone deacetylase inhibitors. Chem. Soc. Rev. 2008, 37, 1402-1413. [CrossRef] [PubMed]

36. Bowlby, M.R.; Peri, R.; Zhang, H.; Dunlop, J. hERG (KCNH2 or Kv11.1) $\mathrm{K}^{+}$channels: Screening for cardiac arrhythmia risk. Curr. Drug Med. 2008, 9, 965-970. [CrossRef]

37. Kerr, J.; Galloway, S.; Lagrutta, A.; Armstrong, M.; Miller, T.; Richon, V.; Andrews, P. Nonclinical Safety Assessment of the Histone Deacetylase Inhibitor Vorinostat. Int. J. Toxicol. 2010, 29, 3-19. [CrossRef] [PubMed]

38. Fukutomi, A.; Hatake, K.; Matsui, K.; Sakajiri, S.; Hirashima, T.; Tanii, H.; Kobayashi, K.; Yamamoto, N. A phase I study of oral panobinostat (LBH589) in Japanese patients with advanced solid tumors. Investig. New Drugs 2011, 30, 1096-1106. [CrossRef] [PubMed]

39. Kovacs, J.J.; Murphy, P.J.M.; Gaillard, S.; Zhao, X.; Wu, J.T.; Nicchitta, C.V.; Yoshida, M.; Toft, D.O.; Pratt, W.B.; Yao, T.P. HDAC6 regulates Hsp90 acetylation and chaperone-dependent activation of glucocorticoid receptor. Mol. Cell 2005, 18, 601-607. [CrossRef] [PubMed]

40. Bali, P.; Pranpat, M.; Bradner, J.; Balasis, M.; Fiskus, W.; Guo, F.; Rocha, K.; Kumaraswamy, S.; Boyapalle, S.; Atadja, P.; Seto, E.; Bhalla, K. Inhibition of histone deacetylase 6 acetylates and disrupts the chaperone function of heat shock protein 90: A novel basis for antileukemia activity of histone deacetylase inhibitors. J. Biol. Chem. 2005, 280, 26729-26734. [CrossRef] [PubMed]

41. Zhong, G.-Q.; Tu, R.-H.; Zeng, Z.-Y.; Li, Q.-J.; He, Y.; Li, S.; Xiao, F. Novel functional role of heat shock protein 90 in protein kinase C-mediated ischemic postconditioning. J. Surg. Res. 2014, 189, 198-206. [CrossRef] [PubMed] 
42. Carystinos, G.D.; Kandouz, M.; Alaoui-Jamali, M.A.; Batist, G. Unexpected induction of the human connexin 43 promoter by the ras signaling pathway is mediated by a novel putative promoter sequence. Mol. Pharmacol. 2003, 63, 821-831. [CrossRef] [PubMed]

43. Saidi Brikci-Nigassa, A.; Clement, M.J.; Ha-Duong, T.; Adjadj, E.; Ziani, L.; Pastre, D.; Curmi, P.A.; Savarin, P. Phosphorylation controls the interaction of the connexin43 C-terminal domain with tubulin and microtubules. Biochemistry 2012, 51, 4331-4342. [CrossRef] [PubMed]

44. Lee, J.-Y.; Koga, H.; Kawaguchi, Y.; Tang, W.; Wong, E.; Gao, Y.-S.; Pandey, U.B.; Kaushik, S.; Tresse, E.; Lu, J.; et al. HDAC6 controls autophagosome maturation essential for ubiquitin-selective quality-control autophagy. EMBO J. 2010, 29, 969-980. [CrossRef] [PubMed]

45. Howes, S.C.; Alushin, G.M.; Shida, T.; Nachury, M.V.; Nogales, E. Effects of tubulin acetylation and tubulin acetyltransferase binding on microtubule structure. Mol. Biol. Cell 2014, 25, 257-266. [CrossRef] [PubMed]

46. Zupkovitz, G.; Tischler, J.; Posch, M.; Sadzak, I.; Ramsauer, K.; Egger, G.; Grausenburger, R.; Schweifer, N.; Chiocca, S.; Decker, T.; et al. Negative and positive regulation of gene expression by mouse histone deacetylase 1. Mol. Cell. Biol. 2006, 26, 7913-7928. [CrossRef] [PubMed]

47. Greim, H.; Albertini, R.J. Cellular response to the genotoxic insult: The question of threshold for genotoxic carcinogens. Toxicol. Res. 2015, 4, 36-45. [CrossRef]

48. Colussi, C.; Rosati, J.; Straino, S.; Spallotta, F.; Berni, R.; Stilli, D.; Rossi, S.; Musso, E.; Macchi, E.; Mai, A.; et al. $\mathrm{N} \varepsilon$-lysine acetylation determines dissociation from GAP junctions and lateralization of connexin 43 in normal and dystrophic heart. Proc. Natl. Acad. Sci. USA 2011, 108, 2795-2800. [CrossRef] [PubMed]

49. Vikram, A.; Lewarchik, C.M.; Yoon, J.-Y.; Naqvi, A.; Kumar, S.; Morgan, G.M.; Jacobs, J.S.; Li, Q.; Kim, Y.-R.; Kassan, M.; et al. Sirtuin 1 regulates cardiac electrical activity by deacetylating the cardiac sodium channel. Nat. Med. 2017, 23, 361-367. [CrossRef] [PubMed]

50. Veenstra, R.D. Voltage clamp limitations of dual whole-cell gap junction current and voltage recordings. I. Conductance measurements. Biophys. J. 2001, 80, 2231-2247. [CrossRef]

(C) 2018 by the authors. Licensee MDPI, Basel, Switzerland. This article is an open access article distributed under the terms and conditions of the Creative Commons Attribution (CC BY) license (http:/ / creativecommons.org/licenses/by/4.0/). 